\title{
Animal Models of Focal Dystonia
}

\author{
Craig Evinger \\ Departments of Neurobiology \& Behavior and Ophthalmology, SUNY Stony Brook, Stony Brook, New York 11794-5230
}

\begin{abstract}
Summary: Animal models indicate that the abnormal movements of focal dystonia result from disordered sensorimotor integration. Sensorimotor integration involves a comparison of sensory information resulting from a movement with the sensory information expected from the movement. Unanticipated sensory signals identified by sensorimotor processing serve as signals to modify the ongoing movement or the planning for subsequent movements. Normally, this process is an effective mechanism to modify neural commands for ongoing movement or for movement planning. Animal models of the focal dystonias spasmodic torticollis, writer's cramp, and benign essential blepharospasm reveal different dysfunctions of sensorimotor integration through which dystonia can arise. Animal models of
\end{abstract}

spasmodic torticollis demonstrate that modifications in a variety of regions are capable of creating abnormal head postures. These data indicate that disruption of neural signals in one structure may mutate the activity pattern of other elements of the neural circuits for movement. The animal model of writer's cramp demonstrates the importance of abnormal sensory processing in generating dystonic movements. Animal models of blepharospasm illustrate how disrupting motor adaptation can produce dystonia. Together, these models show mechanisms by which disruptions in sensorimotor integration can create dystonic movements. Key Words: Spasmodic torticollis, writer's cramp, blepharospasm, sensorimotor integration, dystonia, animal models.
Dystonia is a syndrome characterized by sustained muscle contractions that cause twisting movements or abnormal postures. Although there is a genetic component to dystonia, primary dystonia typically does not result from a clear brain abnormality or lesion. When dystonia involves two or more body segments, it is classified as generalized dystonia. Involvement of only one side of the body is hemidystonia and dystonia affecting only one segment of the body is segmental dystonia. Although some forms of dystonia affect many parts of the body, the syndrome can be limited to a single body part in focal dystonia. Focal dystonias include the uncontrollable spasms of eyelid closure with blepharospasm, the involuntary rotation of the head into abnormal postures with cervical dystonia or spasmodic torticollis, and the spasms of the laryngeal muscles with spasmodic dysphonia. In addition to these focal dystonias, there are occupational dystonias that only appear with one action of the affected body part such as writing with writer's cramp, or embrasure with musician's dystonia in horn players. ${ }^{1-13}$ The focus of the current review is the contribution of animal models of focal dystonia to understanding the neural basis of dystonia.

Address correspondence and reprint requests to Craig Evinger, Departments of Neurobiology \& Behavior and Ophthalmology, SUNY Stony Brook, Stony Brook, NY 11794-5230. E-mail: levinger@notes.cc.sunysb.edu.
There are at least two possible ways to consider generalized and focal dystonia. One hypothesis is that the neural basis for the two syndromes is different. The second position is that generalized and focal dystonia are two ends of a continuum. There is significant support for this latter position. Irrespective of genetic etiology, the form and location of dystonia exhibited by an individual correlates with the age of onset. ${ }^{14}$ Dystonia appearing in children typically begins with the legs and progresses to generalized dystonia. In contrast, the focal dystonia blepharospasm affecting the eyelids usually begins after age 50. To evaluate focal dystonia, it is valuable to first review the neural changes with generalized dystonia.

The best-characterized genetic mutation associated with generalized dystonia is a deletion in the DYT1 gene. Most DYT1 mutations that produce torsion dystonia result from a 3-bp deletion (GAG). ${ }^{15}$ The TorsinA protein encoded by the DYT1 gene is a member of the AAA+ superfamily of ATPases that appears to function in the nuclear envelope. The mutated gene product may disrupt association of the cytoskeleton with the nucleus. ${ }^{16-20}$ This genetic disorder is autosomal dominant with low penetrance, so that the phenotypic expression varies from severe generalized dystonia to no manifestation of the syndrome. ${ }^{14,21,22}$

A DYT1 mutation alters the activity of several brain regions, modifies analysis of sensory information, and 
affects explicit motor learning in humans. Based on positron emission tomography (PET) scans, Eidelberg and colleagues ${ }^{23-25}$ identified a torsion dystonia-related change in the pattern of brain activity. There was abnormal glucose utilization in the posterior putamen/globus pallidus, cerebellum, and supplementary motor area in patients with primary torsion dystonia produced by the DYT1 deletion. This increased metabolism was not the result of dystonic movement because the hypermetabolism was present even when the subjects slept without making movements. The pattern of altered brain metabolism was even present in individuals with the DYT1 mutation who were not symptomatic. The brain regions exhibiting this pattern of abnormal activity have high levels of TorsinA and TorsinB expression. ${ }^{26-28} \mathrm{Al}-$ though TorsinA expression is also high in areas not associated with primary torsion dystonia, the combination of abnormal activity and DYT1 expression suggest that modifications in the activity of a specific set of brain circuits may participate in creating dystonic movements.

In addition to dystonic movements, individuals with primary torsion dystonia also exhibit deficiencies in sensory processing. ${ }^{29-31}$ Primarily, these deficits are in temporal processing. Dystonic patients require significantly longer intervals between stimuli than do control subjects to distinguish whether two somatosensory or two visual stimuli occur asynchronously. Pairing a visual and a somatosensory stimulus exacerbates the difference between controls and individuals with generalized dystonia in their ability to identify temporal differences. ${ }^{30}$ Aglioti et al. $^{30}$ hypothesize that these deficits represent basal ganglia dysfunction. Nevertheless, the evidence that the cerebellum plays a role in temporal processing suggests that the somatosensory processing difficulties may also arise from cerebellar dysfunction. ${ }^{32-35}$ This interpretation is consistent with the data showing that both the basal ganglia and the cerebellum exhibit abnormal activity levels with generalized dystonia. ${ }^{23-25}$

In addition to altered brain and sensory activity, individuals with the DYT1 deletion who do not have dystonic movements manifest deficits in motor learning. Ghilardi and colleagues ${ }^{36}$ show that these individuals exhibit normal implicit motor learning but have difficulties with explicit motor learning tasks. The authors hypothesize that this motor learning deficit in DYT1 carriers results from failures of spatial working memory.

Generalized dystonia only occurs in $30-40 \%$ of individuals with the DYT1 deletion. Individuals with the DYT1 mutation but who do not exhibit dystonic movements show changes in brain metabolism similar to dystonic patients. The existence of comparable brain alterations in dystonic and nondystonic individuals with the same gene mutation demonstrates that the DYT1 mutation alone is insufficient to produce generalized dystonia. ${ }^{6}$ There must be additional factors, environmental or genetic, that lead to the expression of dystonia. Studies of the focal dystonia, benign essential blepharospasm, indicate that dystonia arises from the combination of a predisposing factor, probably genetic, and a second precipitating event, such as motor adaptation to cornea irritation. ${ }^{9,37}$ Applying the hypothesis for the development of benign essential blepharospasm to generalized dystonia may explain why some individuals with the DYT1 deletion exhibit generalized dystonia, but others do not.

Animal models of focal dystonia enable us to dissect out the multiple components that combine to cause dystonia. It is easier to investigate these factors in focal dystonia than generalized dystonia because focal dystonic movements occur on a background of normal movement. Currently, there are animal models of the focal dystonias spasmodic torticollis, writer's cramp, and benign essential blepharospasm. Each of these animal models provides different information about dystonia. Animal models of spasmodic torticollis identify different brain regions, each of which is capable of creating abnormal head postures. The animal model of writer's cramp demonstrates the importance of abnormal sensory processing in creating dystonic movements. Animal models of blepharospasm explore how disrupting motor adaptation can produce dystonia. Together, the models illustrate a valuable way to think about how transformations of sensorimotor integration can create dystonic movements.

\section{SPASMODIC TORTICOLLIS}

Spasmodic torticollis, or cervical dystonia, is a sustained involuntary muscle contraction that rotates the head into an abnormal posture. ${ }^{13,38-41}$ The muscle contractions appear to reflect reduced inhibition in the motor and somatosensory cortex that lead to excessive muscle activation. ${ }^{1,42,43}$ In addition, the overactivity of neck muscles alters motor cortex so that the representation of neck muscles appears to displace the adjacent hand representation. ${ }^{44}$ Similar to patients with generalized dystonia, ${ }^{23-25,45}$ individuals with spasmodic torticollis exhibit increased metabolism in the basal ganglia, thalamus, premotor-motor cortex, and cerebellum. ${ }^{23-25}$ Patients with cervical dystonia also exhibit sensory abnormalities similar to those present in generalized dystonia. There is a reduction in the ability to recognize temporal asynchrony of pairs of spatial stimuli with cervical dystonia, but the ability to identify visual stimuli asynchrony is normal. ${ }^{43}$ Similarly, the perception of vibration induced illusion of movement is subnormal in patients with spasmodic torticollis. ${ }^{46}$ One striking aspect of the sensory changes that occur with cervical dystonia is that approximately $70 \%$ of the patients have a sensory trick that alleviates the dystonic posture. ${ }^{31}$ For example, touching the cheek reduces agonist EMG activity in the dystonic muscle by 
$48 \% .{ }^{47}$ The slower and smaller than normal interaction between the vestibulo-collic reflexes and voluntary movements demonstrates reflex dysfunction in spasmodic torticollis. ${ }^{48}$

Animal models of cervical dystonia recreate the primary symptom of the focal dystonia, sustained abnormal head posture. The data from these studies identify brain regions whose modification reproduces the neck movements of spasmodic torticollis.

Early studies reported that disrupting dopamine in the striatum produced head asymmetry that resembled torticollis. ${ }^{49-52}$ Malouin and Bédard ${ }^{52}$ showed that unilateral electrolytic lesions of the lateral substantia nigra pars reticulata $(\mathrm{SNr})$ produced a sustained contralateral head turn in cats. Electrolytic lesions of the medial forebrain bundle as well as 6-OHDA lesions to deprive the striatum of dopamine caused persistent ipsilateral head turn and reduced head mobility. Disruption of caudate functioning appeared to be the cause of the head asymmetry because injections of dopamine and thyrotropin-releasing hormone into the caudate produced head asymmetry but did not affect head motility. ${ }^{51}$ Although unilateral dopamine depletion of the striatum caused head and postural asymmetries, it is unclear that this modification related directly to human torticollis. The head asymmetry in this animal model required an $80-90 \%$ depletion of dopamine, which produced hemi-Parkinsonism. The effect of these dopamine lesions was probably more a head position bias than a dystonic posture. ${ }^{53}$ Nevertheless, these studies demonstrated that abnormalities in basal ganglia activity could play a role in imposing an abnormal head position.

The observation that neuroleptic drug treatment of typical antipsychotics could elicit acute dystonia and other extrapyramidal side effects ${ }^{54-61}$ is the basis for another animal model of cervical dystonia. Antipsychotic drugs that cause acute dystonia typically have a strong affinity for $\sigma$ receptors. The $\sigma$ receptor is a novel opioid receptor that is naloxone insensitive and steroselective for $(+)$ enantiomers of benzomorphans. ${ }^{61}$ Expression of the receptor is highest in the substantia nigra pars compacta, red nucleus, cerebellum, and many cranial motor nuclei. ${ }^{62-64}$ In alert rats, microinjection of $\sigma$ receptor ligands into the red nucleus produces a marked rotation of the head about the saggital axis, such that the side of the head ipsilateral to the injection rotates upward. This dystonic head posture begins within $10 \mathrm{~min}$ of the injection, peaks approximately $20 \mathrm{~min}$ after the injection and disappears within 60-90 min. ${ }^{65}$ Although some data suggest that both $\sigma_{1}$ and $\sigma_{2}$ receptors play a role in acute human dystonia, ${ }^{66}$ microinjection of $\sigma$ ligands into the rat red nucleus shows that activation of the $\sigma_{2}$, but not the $\sigma_{1}$, receptor causes neck dystonia. ${ }^{67}$ The mechanism through which $\sigma$ agonists injected into the red nucleus produce neck dystonia is unclear. Early studies report that iontophoretic application of $\sigma$ agonists that cause neck dystonia inhibit red nucleus neurons. ${ }^{68,69}$ In contrast, the same investigator finds in a later study that $\sigma$ agonists that cause head torsion in rats prolong burst duration of red nucleus neurons in the in vitro turtle brainstem preparation. ${ }^{70}$ Regardless of the physiological actions of $\sigma$ agonists, however, the data from red nucleus microinjections demonstrate that altering the activity of one of the cerebellum's interfaces with the rest of the brain can acutely cause torticollis-like head postures.

The interstitial nucleus of Cajal (INC) in the midbrain was also identified as a site that might play a role in torticollis in the middle of the previous century. An early study demonstrated that stimulation of the INC produced rotation toward the side of stimulation. ${ }^{71,72}$ There were even attempts to eliminate torticollis with stereotaxic lesions of this region in humans. ${ }^{73,74} \mathrm{~A}$ recent study in nonhuman primates created an animal model of cervical dystonia by showing that altering INC activity disrupted sensorimotor integration of head information. ${ }^{75}$ As with the early study, ${ }^{71}$ Klier et al. ${ }^{75}$ found that microstimulation of INC produced ipsiversive head rotations. Microinjection of muscimol into the INC produced prolonged contraversive torsional head shifts that matched those found in humans with torticollis. ${ }^{76}$ Klier et al. ${ }^{75}$ interpreted their data as showing that the INC is a neural integrator for torsional head position in which the nuclei on each side of the midbrain establish opposite directions of head rotation. As appears to occur for eye movements, a head position neural integrator would convert a signal to turn the head into neural activity appropriate to hold the head in the new position following the movement. If the INC misinterpreted sensory inputs, or there was an imbalance between the two nuclei, then a dystonic head posture would occur. Consistent with this primate model of torticollis, humans with midbrain damage involving the INC exhibited cervical dystonia. ${ }^{77,78}$

Although the animal models of cervical dystonia do not address the basis for the development of the dystonia, they demonstrate that modifying the activity of at least three brain regions can cause a torticollis-like head posture. Two of these regions, the basal ganglia and the cerebellum, are regions that show elevated glucose uptake in generalized ${ }^{23-25}$ and cervical dystonia. ${ }^{79}$ These data indicate that disrupting any component of an interconnected set of brain regions can cause dystonic head movements. Disruptions of INC activity also causes cervical dystonia-like head postures. This region appears to convert efference copy information about the intended head movement into a signal to hold the head in the new position. Altering INC activity appears to be equivalent to the brain misrepresenting the intended or actual head movement, a derangement of sensorimotor integration. The animal model of writer's cramp further illustrates 
the importance of disordered sensory signals from a movement in the generation of focal dystonia.

\section{FOCAL HAND DYSTONIA}

Most focal hand dystonias are task specific in that they primarily occur when an individual performs a certain task such as writing. ${ }^{13,38-40}$ Although there is no evidence for brain lesions causing focal hand dystonias, brain function changes significantly with hand dystonia. Reduced inhibition of motor cortex occurs with writer's cramp. ${ }^{39,80}$ Consistent with these physiological studies, individuals with writer's cramp exhibit reduced GABA levels in cortex. ${ }^{81}$ As with many forms of dystonia, increased excitability or reduced inhibition is present at spinal and brainstem levels with writer's cramp. ${ }^{31,82-84}$ PET imaging reveals a decrease in D2 receptors or receptor binding in the putamen with writer's cramp. ${ }^{85}$ One of the most striking aspects of hand dystonia is that the somatosensory cortex loses its crisp organization with hand dystonia. The hand representation is disordered both for the cortex receiving input from the affected hand ${ }^{86-91}$ and for the cortex receiving input from the unaffected hand. ${ }^{89}$ Associated with the disordered somatosensory cortex organization, individuals with writer's cramp exhibit deficits in somatosensory perception similar to those occurring with torticollis.92-94

Based on their animal model, Byl, Merzenich, and colleagues ${ }^{95-102}$ propose the "sensorimotor learning" hypothesis of focal hand dystonia. This hypothesis emerges from the observation that somatosensory representations in cortex are plastic and can be modified by Hebb-like processes. ${ }^{103-113}$ For example, if a neuron receives nearly simultaneous inputs from a weak and a strong sensory synapse, the weak synapse will gain in strength. In the normal primary somatosensory cortex, area $3 \mathrm{~b}$, there is a precise differentiation of the representation of the fingers. Receptive fields are small and do not include more than one finger. These receptive field properties, however, are modifiable. As an individual practices a hand movement, the movement becomes more efficient and stereotyped. This stereotyped movement causes near simultaneous activation of multiple sensory inputs to somatosensory cortex. If individuals repetitively perform tasks that simultaneously activate multiple somatosensory regions, somatosensory cortex receptive fields can dedifferentiate by responding to previously ineffective sites on the skin. This change occurs as pyramidal neurons receive simultaneous inputs from different skin regions and fingers on already active neurons. ${ }^{114}$ Normally, inhibitory processes prevent cortical networks from being re-excited by an input for several hundred milliseconds after the arrival of the first stimulus. In focal dystonia, however, the magnitude and duration of inhibitory processes decrease, ${ }^{42}$ which facilitates this abnormal linking of so- matosensory signals. As cortical somatosensory receptive fields dedifferentiate, the "sensorimotor learning" hypothesis posits that individuals become less able to integrate sensory and motor signals that makes movement dystonic. In a variation on this theme, Sanger and Merzernich ${ }^{102}$ propose that an increased gain produced by abnormal linking of different somatosensory responses causes focal dystonia.

Byl and colleagues ${ }^{95-97,115,116}$ required owl monkeys to perform repetitive hand movements to receive rewards. Before beginning the task and again after the monkeys developed dystonic hand movements, the investigators measured area $3 b$ receptive fields for the hand. In one task, ${ }^{96,97,115}$ two monkeys were required to hold on to a hand piece molded to fit the hand. While the monkey gripped the hand piece, it opened and closed by $6.4 \mathrm{~mm}$ one to nine times. If the monkey maintained its grip by keeping all of its fingers on the hand piece, the monkey received a reward. The monkeys performed 300 trials per day in which they received 1100-3000 opening and closings of the hand in a 1- to 2-h period. Training occurred 5 or 6 days a week over a 12- to 25-week period. Both monkeys developed hand dystonia so that fingers pulled away from the hand piece as the monkey attempted to grasp it. In another study, ${ }^{116}$ the investigators made another three monkeys perform repetitive squeezing of a hand piece for reward. Two of the monkeys developed hand dystonia within 5 or 24 weeks. The third monkey began with a hand squeezing strategy, but switched to a variable arm pulling procedure in the second week of training. This animal did not develop dystonic hand movements within 24 weeks of training. The dystonic movements in these monkeys did not result from inflammation of the tendons or hand caused by repetitive hand movements. ${ }^{116}$ The change in hand representation in the somatosensory cortex that accompanied hand dystonia in these monkeys, however, was dramatic. Receptive field size was 10-20 times larger than normal and receptive fields frequently included more than one distal digit. As occurred with human writer's cramp, ${ }^{89}$ monkeys also showed enlarged receptive fields in the cortex receiving inputs from the hand not used in the task. ${ }^{115}$

The dramatic transformation in somatosensory cortex representation of the hand in human writer's cramp could cause the syndrome or simply reflect the altered sensory signals produced by the dystonic movements. ${ }^{117}$ Although the monkey model of hand dystonia cannot distinguish between these two possibilities, the sensorimotor learning hypothesis argues that the dedifferentiation of somatosensory cortex causes hand dystonia. The animal model studies support this interpretation because somatosensory cortex was normal before training but dedifferentiated with the development of dystonic hand movements. It is surprising, however, that monkeys can 
develop focal hand dystonia with only 216,000 occurrences of the hand piece opening and closing. Before developing a task-related focal dystonia, a human experiences many more repetitions of a movement than the monkeys. For example, writer's cramp usually appears around age $38,{ }^{14}$ after the individual has written for at least 32 years. Moreover, the majority of individuals never develop writer's cramp in a lifetime of writing. Although these observations from humans indicate the necessity of a predisposing factor in the development of writer's cramp, the animal model demonstrates that a disruption of the sensory processing from a movement is a critical component of this focal dystonia.

\section{BLEPHAROSPASM}

The dystonic movements of blepharospasm are involuntary spasms of bilateral eyelid closure. ${ }^{9,37}$ In addition to lid spasms, subjects exhibit an increased spontaneous blink rate that may result from the increased excitability of the trigeminal system that is a constituent of blepharospasm. ${ }^{118-120}$ This focal dystonia typically appears later in life than any other dystonia, usually after age 50. ${ }^{7,9,37,121,122}$ PET and functional magnetic resonance imaging studies of blepharospasm patients reveal hyperactivity of brain regions typical of other forms of dystonia, frontal cortex, striatum, thalamus, and cerebellum. ${ }^{123-127}$ There appear to be three general categories of blepharospasm: 1) benign essential blepharospasm, an idiopathic focal dystonia; 2) reflex blepharospasm, a syndrome associated with dopamine depletion; and 3) Bell's palsy associated blepharospasm, a syndrome concomitant with facial palsy. There are animal models that reproduce reflex blepharospasm and benign essential blepharospasm.

The evidence linking blepharospasm to basal ganglia dysfunction $^{9,85,123-125}$ led investigators to modify dopamine levels to model reflex blepharospasm in animals. The blink system is exquisitely sensitive to dopamine levels. The excitability of trigeminal reflex blinks increases as dopamine is lost with normal aging. ${ }^{128}$ Elevated dopamine levels increase the rate of spontaneous blinking. ${ }^{129-135}$ Despite this increased blink rate, elevated dopamine levels or systemic treatment with apomorphine, a $\mathrm{D}_{2} / \mathrm{D}_{1}$ receptor agonist, reduces trigeminal reflex blink excitability and the speed of lid closure. ${ }^{136-138}$ Conversely, destroying the majority of nigral dopamine neurons with catecholamine-specific toxins such as 6-OHDA, or as a result of Parkinson's disease, dramatically decreases the spontaneous blink rate but increases the excitability of trigeminal reflex blinks. ${ }^{139-148}$ This elevated trigeminal excitability can be sufficient for a strong trigeminal stimulus such as touching the cornea to cause involuntary spasms of lid closure in humans ${ }^{149-151}$ and rats. ${ }^{140}$

In addition to the reflex blepharospasm in rats caused

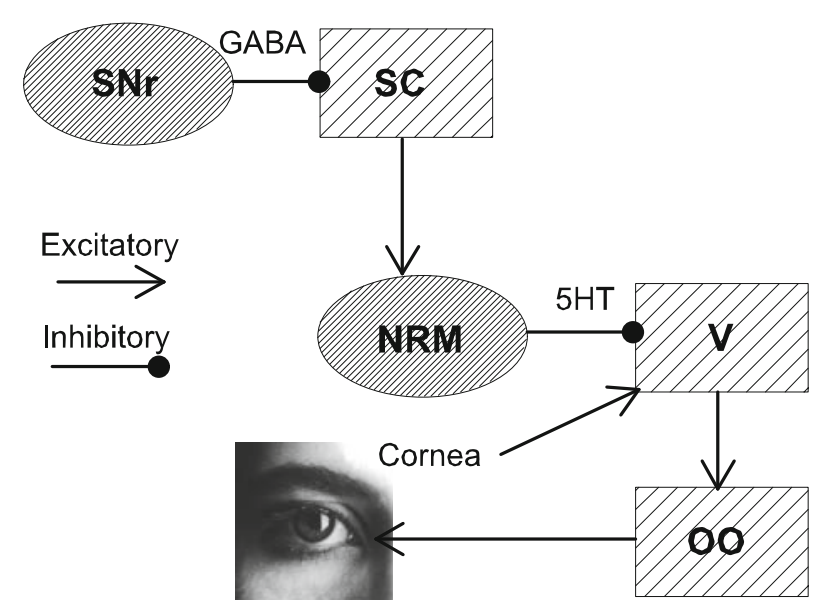

FIG. 1. Schematic of the circuit through which the basal ganglia modulates trigeminal reflex blink excitability from Basso et al. ${ }^{155}$ $\mathrm{NRM}=$ nucleus raphe magnus; $\mathrm{OO}=$ orbicularis oculi motoneurons in the facial nucleus; $S C=$ superior colliculus; $V=$ spinal trigeminal complex.

by 6-OHDA lesions of the substantia nigra pars compacta, ${ }^{140}$ systemic injection of the catecholamine depleting compound, Ro 4-1284, produced a reserpine syndrome in mice and rats that included lid closures described as blepharospasm. ${ }^{152}$ The characteristics of blepharospasm in this study, however, were unclear. A later study ${ }^{153}$ reported that Ro 4-1284 increased blink rate from a predrug rate of $0.34 \mathrm{blinks} / \mathrm{min}$ to $1.42 \mathrm{blinks} / \mathrm{min}$ after 10 days of Ro 4-1284 treatment. Although these results appear to conflict with previous observations that dopamine reduction depresses the spontaneous blink rate, it is unclear whether the investigators measured spontaneous blinks or increased reflex blinking from elevated trigeminal excitability caused by dopamine depletion.

Although the circuits through which dopamine modulates spontaneous blink rate are unknown, Basso and colleagues ${ }^{154,155}$ have determined how the basal ganglia regulate trigeminal reflex blink excitability (FIG. 1). This circuit accounts for the reflex blepharospasm resulting from dopamine depletion. GABAergic (GABA) $\mathrm{SNr}$ inhibit neurons in the intermediate layers of the superior colliculus (SC). These neurons excite a small group of neurons in the nucleus raphe magnus (NRM). These serotonergic (5HT) nucleus raphe magnus neurons inhibit trigeminal reflex blink circuits $(\mathrm{V})$, which innervate the lid closing, orbicularis oculi motoneurons (OO). The dopamine depletion of Parkinson's disease increases substantia nigra pars reticulata inhibition of superior colliculus neurons. ${ }^{156}$ The consequent reduction of nucleus raphe magnus neuron excitation from the superior colliculus decreases inhibition of the trigeminal blink circuit, thereby increasing its excitability. Conversely, elevating basal ganglia dopamine levels causes an increase in nucleus raphe magnus inhibition of the blink circuits that reduces trigeminal blink excitability. 


\section{Dry Eye}

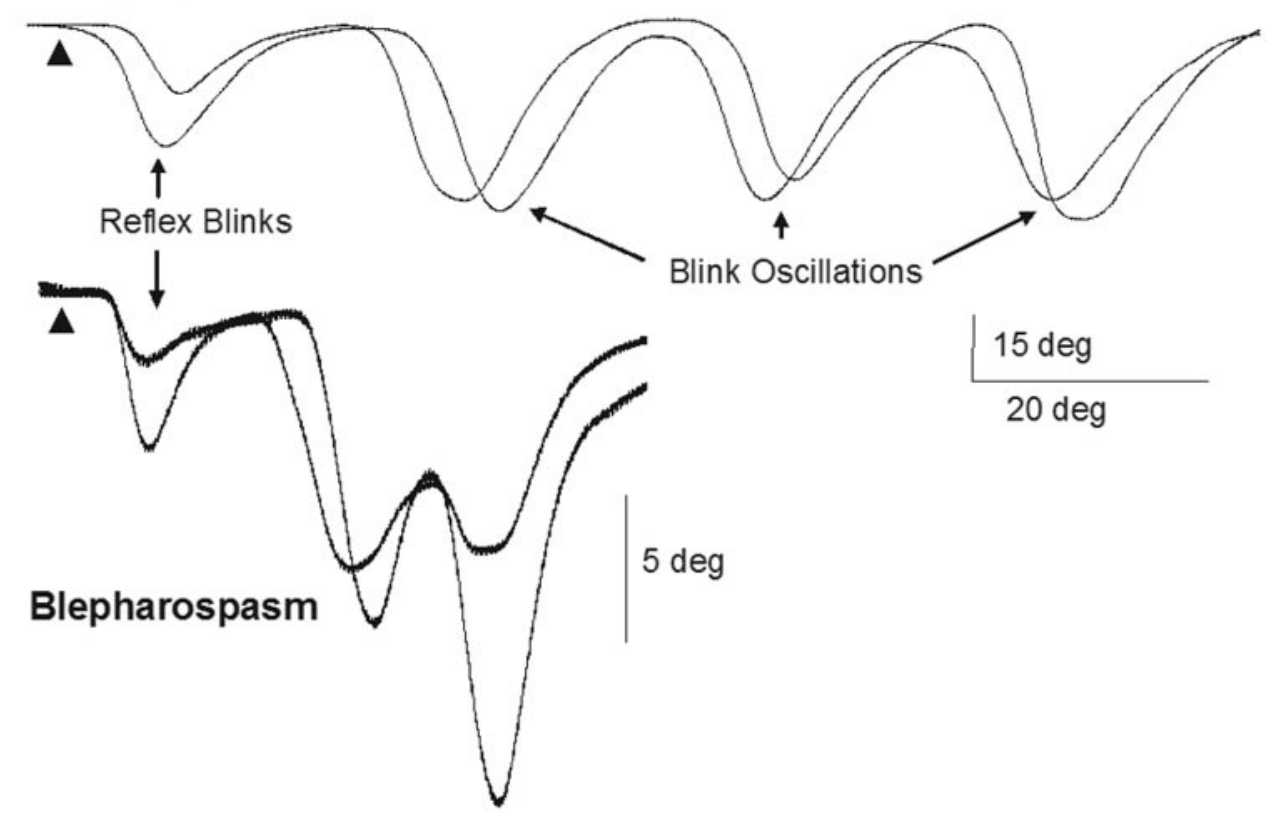

FIG. 2. Reflex blinks and blink oscillations (dry eye) and spasm of lid closure (blepharospasm) elicited by stimulation of the supraorbital branch of the trigeminal nerve (A). Top traces are two consecutive trials from a human subject with dry eye. Bottom traces are two consecutive trials from a human subject with benign essential blepharospasm. Each trace is a single trial. The spasms of lid closure with blepharospasm appear to be blink oscillations with a very short interblink interval.

The development of reflex blepharospasm rather than benign essential blepharospasm with nigral dopamine depletion does not rule out a role for dopamine in the development of this focal dystonia. Recent genetic evidence from patients with benign essential blepharospasm shows a modification in the gene for the $\mathrm{D}_{5}$ receptor. ${ }^{157,158}$ Future animal studies need to explore the function of the $\mathrm{D}_{5}$ receptor in blinking.

Schicatano and colleagues ${ }^{159}$ created a two-component model of benign essential blepharospasm based on the explanation usually put forth for the development of human blepharospasm. Dystonia arises from the combination of a permissive condition and a precipitating event. ${ }^{9,37}$ Benign essential blepharospasm patients frequently come to the clinic with an initial complaint of dry eye. ${ }^{119}$ Therefore, Schicatano and colleagues ${ }^{120}$ reasoned that cornea irritation might be the precipitating event for the development of benign essential blepharospasm. The normal adaptive response to dry eye or eye irritation is to increase trigeminal reflex blink excitability and to generate additional large amplitude blinks in response to a trigeminal reflex blink stimulus. These additional blinks are called blink oscillations (FIG. 2). Because blink oscillations with dry eye occur with a constant interblink interval, the investigators proposed that the spasms of lid closure of blepharospasm were an exaggeration of the normally compensatory process evoked by dry eye or eye irritation. To create the permissive component of benign essential blepharospasm that would allow an exaggerated response to dry eye, the investigators produced a small, unilateral lesion of substantia nigra pars compacta dopaminergic neurons. By itself, this small 6-OHDA lesion of dopamine neurons slightly increased trigeminal reflex blink excitability but did not generate reflex blepharospasm or spasms of lid closure. To create the precipitating factor, the zygomatic branch of the facial nerve was crushed to transiently eliminate approximately $30 \%$ of the orbicularis oculi innervation. By itself, this procedure induced a mild dry eye, which slightly increased trigeminal reflex blink excitability and resulted in the development of blink oscillations similar to that seen in human dry eye. Combining the two procedures, however, dramatically elevated trigeminal reflex blink excitability, increased spontaneous blinking, and caused long-lasting spasms of lid closure similar to benign essential blepharospasm. These blepharospasm-like characteristics continued after the facial nerve regained full function and eliminated the dry eye. Thus, this animal model recreated many of the characteristics of the focal dystonia benign essential blepharospasm.

As occurs in focal dystonia ${ }^{40,93,160}$ and generalized dystonia, ${ }^{29,30,160}$ the animal model of benign essential blepharospasm ${ }^{159}$ creates dysfunctional sensorimotor integration in which the nervous system either misinterprets sensory signals or misrepresents the desired movement. Sensorimotor integration continuously adjusts the eyelid system to maintain cornea integrity. These adjustments, motor adaptations, result from interactions among 
the activity of cornea afferents, sensory inputs from the eyelid movement, and a model of the sensory signals anticipated from the eyelid movement. Altering any component of this triad transforms the signals of the other two components. For example, reducing eyelid motility increases afferent input from the cornea because of dry eye and produces an unexpectedly small sensory signal from the attempted eyelid movement relative to the intended eyelid movement. This change in the sensory signals revises the inputs to the eyelid motor circuits in an attempt to reduce cornea afferent input and generate a blink equivalent to the expected lid movement through long-term potentiation- and long-term depression-like modifications of trigeminal blink circuits. ${ }^{161}$ The increased cornea afferent input also transforms the trigeminal reflex blink circuit from a single response circuit into a damped oscillator (FIG. 2). ${ }^{120}$

The neural basis of generating dystonic spasms of eyelid closure is unknown. Data from animal and human studies, however, suggest that the cerebellum may be crucial in this process. The cerebellum is essential for eyelid adaptation to reduced eyelid motility. ${ }^{162}$ Interpositus neurons of the cerebellum activate lid closing, orbicularis oculi motoneurons via the red nucleus ${ }^{163-165}$ and also modulate trigeminal complex neuronal activity. ${ }^{166}$ Thus, the cerebellum participates in sensorimotor processing and modulates blink circuits. There is abundant evidence from animal studies that the cerebellum is important in generalized dystonia. ${ }^{167-171}$ Low-dose injection of kainic acid into the mouse cerebellum causes a transient generalized dystonia including spasms of lid closure. These dystonic postures result from glutamatergic modifications of Purkinje cell discharge because transgenic mice lacking Purkinje cells do not exhibit dystonic posturing following kainic acid injections into the vermis ${ }^{169}$ (see Hess and colleagues ${ }^{170}$ in this issue). In a genetically dystonic rat (dt), deep cerebellar nucleus neurons exhibit a bursting rather than a tonic discharge pattern and removal of the cerebellum eliminates dystonic posturing. ${ }^{167,171,172}$ This bursting discharge pattern parallels the activity of the orbicularis oculi muscle during eyelid spasms. The cerebellum may modulate the excitability of the facial nucleus and/or interact with other neural structures to create an oscillatory pattern in reflex blink circuits that can convert into spasms of lid closure in the presence of a permissive condition, such as sensorimotor dysfunction.

\section{IMPLICATIONS OF ANIMAL MODELS OF FOCAL DYSTONIA}

Human data suggest that dystonia may be a continuum of syndromes from generalized to focal dystonias. Regardless of genetic background, the type of dystonia depends upon the age of development. ${ }^{6,14}$ In generalized dystonia appearing in children, the dystonic movements begin in the legs, whereas cranial dystonias appear after age 50 and do not progress to generalized dystonia. Most imaging studies in both generalized and focal dystonias report that the same brain regions exhibit increased glucose uptake or blood flow. ${ }^{23,80,85,89,123-125,127,173,174}$ In virtually all cases of primary dystonia, there is dysfunction of the thalamus, frontal cortex, cerebellum, and basal ganglia, particularly the striatum. These altered activity patterns at least partially reflect a reduction in cortical inhibition. ${ }^{42,117}$ Finally, abnormalities in sensory processing accompany all forms of dystonia. ${ }^{29,31}$ Animal models reinforce these clinical observations. Generalized dystonia in the genetically dt rat results exclusively from modifications in the cerebellum. ${ }^{167,170,172,175}$ In contrast, generalized dystonia in the genetically dystonic hamster $\mathrm{dt}(\mathrm{sz})$ appear primarily to create basal ganglia dysfunction. ${ }^{176-186}$ These generalized dystonia models imply that disruption anywhere in the sensorimotor circuit can produce dystonia. For example, microinjection of $\sigma$ receptor agonists into the red nucleus causes cervical dystonia. ${ }^{66,70}$ Modification of basal ganglia function enables the development of blepharospasm. ${ }^{159}$ Thus, animal models of dystonia reveal that disruption in a variety of brain regions can cause dystonia. Alterations in sensory processing are concomitant with these motor system transformations. Indeed, data from the animal model of hand dystonia suggest that degradation of the hand representation in somatosensory cortex alone is sufficient to produce dystonic hand movements. ${ }^{98}$ These types of data point to the conclusion that dystonia results from a disruption of sensorimotor integration.

Sensorimotor integration may be a comparison of sensory information resulting from a movement with the sensory information expected from the movement. Inherent to this concept is the postulation that the nervous system has learned the sensations that a specific motor command should generate. Based on this knowledge, unanticipated sensory signals identified by sensorimotor processing can serve as signals to modify the ongoing movement or subsequent movements. Normally, this process provides an effective and unconscious way to adapt neural commands to internal or external changes in the movement environment. Several lines of evidence suggest that the cerebellum plays an important role in this process. ${ }^{187-191}$ Nevertheless, sensorimotor integration for complicated actions such as hand movements probably engages multiple brain regions such as motor cortex areas, basal ganglia, somatosensory cortex, and cerebellum. Disruption of neural signals in any structure could mutate the activity pattern in all of the others. For example, if the basal ganglia fails to suppress competing motor commands of a specific movement, ${ }^{192,193}$ then sensorimotor integration should recognize the unanticipated sensory signals from the movement and attempt to 
compensate for them. If sensorimotor processing is abnormal in dystonia, the brain will not identify the movement as anomalous. Dedifferentiation of the hand representation of somatosensory cortex can provide unanticipated sensory information from a normal movement. The attempt to correct this illusory error may produce dystonic hand movements. Disruptions of primary motor cortex can create motor commands in which the movement does not match the anticipated sensory consequences. Animal models of focal dystonia provide powerful tools to analyze these complex interactions. Understanding modifications in sensorimotor processing in focal dystonia may help establish how genetic mutations combine with the environment to create generalized dystonia.

Acknowledgments: This work supported by a grant from the National Eye Institute (EY07391) to the author.

\section{REFERENCES}

1. Berardelli A, Rothwell JC, Hallett M, Thompson PD, Manfredi M, Marsden CD. The pathophysiology of primary dystonia. Brain 121(Pt 7):1195-1212, 1998.

2. Hallett M. Physiology of dystonia. Adv Neurol 78:11-18, 1998.

3. Berardelli A, Curra A. Pathophysiology and treatment of cranial dystonia. Mov Disord 17 [Suppl 2]:S70-S74, 2002.

4. Fahn S. Blepharospasm: a form of focal dystonia. Adv Neurol 49:125-133, 1988.

5. Bressman SB. Dystonia: phenotypes and genotypes. Rev Neurol (Paris) 159(10 Pt 1):849-856, 2003.

6. Saunders-Pullman R, Shriberg J, Shanker V, Bressman SB. Penetrance and expression of dystonia genes. Adv Neurol 94:121125, 2004.

7. Bressman SB. Dystonia genotypes, phenotypes, and classification. Adv Neurol 94:101-107, 2004.

8. Fahn S, Bressman SB, Marsden CD. Classification of dystonia. Adv Neurol 78:1-10, 1998.

9. Hallett M. Blepharospasm: recent advances. Neurology 59:13061312, 2002.

10. Pettigrew LC, Jankovic J Hemidystonia: a report of 22 patients and a review of the literature. J Neurol Neurosurg Psychiatry 48:650-657, 1985.

11. Greene P, Kang UJ, Fahn S. Spread of symptoms in idiopathic torsion dystonia. Mov Disord 10:143-152, 1995.

12. Jankovic J, Shale H. Dystonia in musicians. Semin Neurol 9:1311351989

13. Lim VK, Altenmuller E, Bradshaw JL. Focal dystonia: current theories. Hum Mov Sci 20:875-914, 2001.

14. O'Riordan S, Raymond D, Lynch T, Saunders-Pullman R, Bressman SB, Daly L, et al. Age at onset as a factor in determining the phenotype of primary torsion dystonia. Neurology 63:1423-1426, 2004.

15. Ozelius LJ, Hewett JW, Page CE, Bressman SB, Kramer PL, Shalish C, et al. The early-onset torsion dystonia gene (DYT1) encodes an ATP-binding protein. Nat Genet 17:40-48, 1997.

16. Breakefield XO, Kamm C, Hanson PI. TorsinA: movement at many levels. Neuron 31:9-12, 2001

17. Goodchild RE, Dauer WT. Mislocalization to the nuclear envelope: an effect of the dystonia-causing torsinA mutation. Proc Natl Acad Sci USA 101:847-852, 2004.

18. Naismith TV, Heuser JE, Breakefield XO, Hanson PI. TorsinA in the nuclear envelope. Proc Natl Acad Sci USA 101:7612-7617, 2004.

19. Dauer W, Goodchild R. Mouse models of torsinA dysfunction. Adv Neurol 94:67-72, 2004.
20. Caldwell GA, Cao S, Sexton EG, Gelwix CC, Bevel JP, Caldwell KA. Suppression of polyglutamine-induced protein aggregation in Caenorhabditis elegans by torsin proteins. Hum Mol Genet 12:307-319, 2003.

21. Opal P, Tintner R, Jankovic J, Leung J, Breakefield XO, Friedman J, et al. Intrafamilial phenotypic variability of the DYT1 dystonia: from asymptomatic TOR1A gene carrier status to dystonic storm. Mov Disord 17:339-345, 2002.

22. Edwards MJ, Huang YZ, Wood NW, Rothwell JC, Bhatia KP. Different patterns of electrophysiological deficits in manifesting and non-manifesting carriers of the DYT1 gene mutation. Brain 126(Pt 9):2074-2080, 2003.

23. Eidelberg D, Moeller JR, Antonini A, Kazumata K, Nakamura T, Dhawan V, et al. Functional brain networks in DYT1 dystonia. Ann Neurol 44:303-312, 1998.

24. Eidelberg D. Abnormal brain networks in DYT1 dystonia. Adv Neurol 78:127-133, 1998.

25. Trost M, Carbon M, Edwards C, Ma Y, Raymond D, Mentis MJ, et al. Primary dystonia: is abnormal functional brain architecture linked to genotype? Ann Neurol 52:853-856, 2002.

26. Augood SJ, Penney JB Jr, Friberg IK, Breakefield XO, Young $\mathrm{AB}$, Ozelius LJ, et al. Expression of the early-onset torsion dystonia gene (DYT1) in human brain. Ann Neurol 43:669-673, 1998.

27. Augood SJ, Martin DM, Ozelius LJ, Breakefield XO, Penney JB $\mathrm{Jr}$, Standaert DG. Distribution of the mRNAs encoding torsinA and torsinB in the normal adult human brain. Ann Neurol 46:761$769,1999$.

28. Konakova M, Pulst SM. Immunocytochemical characterization of torsin proteins in mouse brain. Brain Res 922:1-8, 2001.

29. Tinazzi M, Rosso T, Fiaschi A. Role of the somatosensory system in primary dystonia. Mov Disord 18:605-622, 2003.

30. Aglioti SM, Fiorio M, Forster B, Tinazzi M. Temporal discrimination of cross-modal and unimodal stimuli in generalized dystonia. Neurology 60:782-785, 2003.

31. Abbruzzese G, Berardelli A. Sensorimotor integration in movement disorders. Mov Disord 18:231-240, 2003.

32. Miall RC, Weir DJ, Wolpert DM, Stein JF. Is the cerebellum a Smith predictor? J Mot Behav 25:203-216, 1993.

33. Ivry RB, Spencer RM, Zelaznik HN, Diedrichsen J. The cerebellum and event timing. Ann NY Acad Sci 978:302-317, 2002.

34. Ivry RB, Spencer RM. The neural representation of time. Curr Opin Neurobiol 14:225-232, 2004.

35. Nixon PD. The role of the cerebellum in preparing responses to predictable sensory events. Cerebellum 2:114-122, 2003.

36. Ghilardi MF, Carbon M, Silvestri G, Dhawan V, Tagliati M, Bressman S, et al. Impaired sequence learning in carriers of the DYT1 dystonia mutation. Ann Neurol 54:102-109, 2003.

37. Hallett M, Daroff RB. Blepharospasm: report of a workshop. Neurology 46:1213-1218, 1996.

38. Marsden CD. The focal dystonias. Clin Neuropharmacol 9[Suppl 2]:S49-S60, 1986.

39. Chen R, Hallett M. Focal dystonia and repetitive motion disorders. Clin Orthop 351:102-106, 1998.

40. Hallett M. The neurophysiology of dystonia. Arch Neurol 55: 601-603, 1998.

41. Dauer WT, Burke RE, Greene P, Fahn S. Current concepts on the clinical features, aetiology and management of idiopathic cervical dystonia. Brain 121(Pt 4):547-560, 1998.

42. Hallett M. Dystonia: abnormal movements result from loss of inhibition. Adv Neurol 94:1-9, 2004.

43. Tinazzi M, Fiorio M, Bertolasi L, Aglioti SM. Timing of tactile and visuo-tactile events is impaired in patients with cervical dystonia. J Neurol 251:85-90, 2004.

44. Thickbroom GW, Byrnes ML, Stell R, Mastaglia FL. Reversible reorganisation of the motor cortical representation of the hand in cervical dystonia. Mov Disord 18:395-402, 2003.

45. Eidelberg D. Functional brain networks in movement disorders. Curr Opin Neurol 11:319-326, 1998.

46. Frima N, Rome SM, Grunewald RA. The effect of fatigue on abnormal vibration induced illusion of movement in idiopathic focal dystonia. J Neurol Neurosurg Psychiatry 74:1154-1156, 2003. 
47. Schramm A, Reiners K, Naumann M. Complex mechanisms of sensory tricks in cervical dystonia. Mov Disord 19:452-458, 2004.

48. Munchau A, Corna S, Gresty MA, Bhatia KP, Palmer JD, Dressler D, et al. Abnormal interaction between vestibular and voluntary head control in patients with spasmodic torticollis. Brain 124(Pt 1):47-59, 2001.

49. Crossman AR, Sambrook MA. Experimental torticollis in the monkey produced by unilateral 6-hydroxy-dopamine brain lesions. Brain Res 149:498-502, 1978.

50. Malouin F, Bedard PJ. Frontal torticollis (head tilt) induced by electrolytic lesion and kainic acid injection in monkeys and cats. Exp Neurol 78:551-560, 1982.

51. Malouin F, Bedard PJ. Head turning induced by unilateral intracaudate thyrotropin-releasing hormone (TRH) injection in the cat. Eur J Pharmacol 81:559-567, 1982.

52. Malouin F, Bedard PJ. Evaluation of head motility and posture in cats with horizontal torticollis. Exp Neurol 81:559-570, 1983.

53. Henderson JM, Watson S, Halliday GM, Heinemann T, Gerlach M. Relationships between various behavioural abnormalities and nigrostriatal dopamine depletion in the unilateral 6-OHDA-lesioned rat. Behav Brain Res 139:105-113, 2003.

54. Wirshing WC. Movement disorders associated with neuroleptic treatment. J Clin Psychiatry 62 [Suppl 21]:15-18, 2001.

55. Ramesh S, Sagar R. Antipsychotic induced movement disorders. Indian J Med Sci 55:483-487, 2001.

56. Houltram B, Scanlan M. Extrapyramidal side effects. Nurs Stand 18:39-41, 2004.

57. Casey DE. Pathophysiology of antipsychotic drug-induced movement disorders. J Clin Psychiatry 65 [Suppl 9]:25-28, 2004.

58. Jeanjean AP, Laterre EC, Maloteaux JM. Neuroleptic binding to $\sigma$ receptors: possible involvement in neuroleptic-induced acute dystonia. Biol Psychiatry 41:1010-1019, 1997.

59. Walker FO, Walker JM, Matsumoto RR, Bowen WD. Torticollis, midbrain, and $\sigma$ receptors. Mov Disord 5:265, 1990.

60. Walker JM, Matsumoto RR, Bowen WD, Gans DL, Jones KD, Walker FO. Evidence for a role of haloperidol-sensitive $\sigma$-'opiate' receptors in the motor effects of antipsychotic drugs. Neurology 38:961-965, 1988.

61. Walker JM, Bowen WD, Walker FO, Matsumoto RR, De Costa B, Rice KC. $\sigma$ Receptors: biology and function. Pharmacol Rev 42:355-402, 1990.

62. Largent BL, Gundlach AL, Snyder SH. Psychotomimetic opiate receptors labeled and visualized with (+)-[3H]3-(3-hydroxyphenyl)-N-(1-propyl)piperidine. Proc Natl Acad Sci USA 81:4983-4987, 1984.

63. Gundlach AL, Largent BL, Snyder SH. Autoradiographic localization of $\sigma$ receptor binding sites in guinea pig and rat central nervous system with (+)3H-3-(3-hydroxyphenyl)-N-(1-propy1)piperidine. J Neurosci 6:1757-1770, 1986.

64. Shamsul Ola M, Moore P, El-Sherbeny A, Roon P, Agarwal N, Sarthy VP, et al. Expression pattern of $\sigma$ receptor $1 \mathrm{mRNA}$ and protein in mammalian retina. Brain Res Mol Brain Res 95:86-95, 2001.

65. Okumura K, Ujike H, Akiyama K, Kuroda S. BMY-14802 reversed the $\sigma$ receptor agonist-induced neck dystonia in rats. J Neural Transm 103:1153-1161, 1996.

66. Matsumoto RR, Pouw B. Correlation between neuroleptic binding to $\sigma(1)$ and $\sigma(2)$ receptors and acute dystonic reactions. Eur J Pharmacol 401:155-160, 2000.

67. Nakazawa M, Kobayashi T, Matsuno K, Mita S. Possible involvement of a $\sigma$ receptor subtype in the neck dystonia in rats. Pharmacol Biochem Behav 62:123-126, 1999.

68. Matsumoto RR, Walker JM. Inhibition of rubral neurons by a specific ligand for $\sigma$ receptors. Eur J Pharmacol 158:161-165, 1988.

69. Matsumoto RR, Walker JM. Iontophoretic effects of $\sigma$ ligands on rubral neurons in the rat. Brain Res Bull 29:419-425, 1992.

70. Matsumoto RR, Bowen WD, de Costa BR, Houk JC. Relationship between modulation of the cerebellorubrospinal system in the in vitro turtle brain and changes in motor behavior in rats: effects of novel $\sigma$ ligands. Brain Res Bull 48:497-508, 1999.
71. Hassler R, Hess WR. [Experimental and anatomical findings in rotatory movements and their nervous apparatus.] Arch Psychiatr Nervenkr Z Gesamte Neurol Psychiatr 192:488-526, 1954.

72. Kiss Z. Everything old is new again? Science 297:335-336; author reply 335-336, 2002.

73. Sano K, Yoshioka M, Mayanagi Y, Sekino H, Yoshimasu N. Stimulation and destruction of and around the interstitial nucleus of Cajal in man. Confin Neurol 32:118-125, 1970.

74. Sano K, Sekino H, Tsukamoto Y, Yoshimasu N, Ishijima B. Stimulation and destruction of the region of the interstitial nucleus in cases of torticollis and see-saw nystagmus. Confin Neurol 34:331-338, 1972.

75. Klier EM, Wang H, Constantin AG, Crawford JD. Midbrain control of three-dimensional head orientation. Science 295:1314 1316, 2002.

76. Medendorp WP, van Gisbergen JA, Horstink MW, Gielen CC Donders' law in torticollis. J Neurophysiol 82:2833-2838, 1999.

77. Ohashi T, Fukushima K, Chin S, Harada T, Yoshida K, Akino M, et al. Ocular tilt reaction with vertical eye movement palsy caused by localized unilateral midbrain lesion. J Neuroophthalmol 18: 40-42, 1998.

78. Halmagyi GM, Brandt T, Dieterich M, Curthoys IS, Stark RJ, Hoyt WF. Tonic contraversive ocular tilt reaction due to unilateral meso-diencephalic lesion. Neurology 40:1503-1509, 1990.

79. Galardi G, Perani D, Grassi F, Bressi S, Amadio S, Antoni M, et al. Basal ganglia and thalamo-cortical hypermetabolism in patients with spasmodic torticollis. Acta Neurol Scand 94:172-176, 1996.

80. Ibanez V, Sadato N, Karp B, Deiber MP, Hallett M. Deficient activation of the motor cortical network in patients with writer's cramp. Neurology 53:96-105, 1999.

81. Levy LM, Hallett M. Impaired brain GABA in focal dystonia. Ann Neurol 51:93-101, 2002.

82. Tolosa E, Montserrat L, Bayes A. Blink reflex studies in patients with focal dystonias. Adv Neurol 50:517-524, 1988.

83. Grunewald RA, Yoneda Y, Shipman JM, Sagar HJ. Idiopathic focal dystonia: a disorder of muscle spindle afferent processing? Brain 120(Pt 12):2179-2185, 1997.

84. Yoneda Y, Rome S, Sagar HJ, Grunewald RA. Abnormal perception of the tonic vibration reflex in idiopathic focal dystonia. Eur J Neurol 7:529-533, 2000.

85. Perimutter JS, Stambuk MK, Markham J, Black KJ, McGeeMinnich L, Jankovic J, et al. Decreased [18F]spiperone binding in putamen in idiopathic focal dystonia. J Neurosci 17:843-850, 1997.

86. Candia V, Wienbruch C, Elbert T, Rockstroh B, Ray W. Effective behavioral treatment of focal hand dystonia in musicians alters somatosensory cortical organization. Proc Natl Acad Sci USA 100:7942-7946, 2003.

87. Bara-Jimenez W, Catalan MJ, Hallett M, Gerloff C. Abnormal somatosensory homunculus in dystonia of the hand. Ann Neurol 44:828-831, 1998.

88. Murase N, Kaji R, Shimazu H, Katayama-Hirota M, Ikeda A, Kohara N, et al. Abnormal premovement gating of somatosensory input in writer's cramp. Brain 123(Pt 9):1813-1829, 2000.

89. Meunier S, Garnero L, Ducorps A, Mazieres L, Lehericy S, du Montcel ST, et al. Human brain mapping in dystonia reveals both endophenotypic traits and adaptive reorganization. Ann Neurol 50:521-527, 2001.

90. Butterworth S, Francis S, Kelly E, McGlone F, Bowtell R, Sawle GV. Abnormal cortical sensory activation in dystonia: an fMRI study. Mov Disord 18:673-682, 2003.

91. Elbert T, Candia V, Altenmuller E, Rau H, Sterr A, Rockstroh B, et al. Alteration of digital representations in somatosensory cortex in focal hand dystonia. Neuroreport 9:3571-3575, 1998.

92. Tinazzi M, Fiaschi A, Frasson E, Fiorio M, Cortese F, Aglioti SM. Deficits of temporal discrimination in dystonia are independent from the spatial distance between the loci of tactile stimulation. Mov Disord 17:333-338, 2002.

93. Abbruzzese G, Marchese R, Buccolieri A, Gasparetto B, Trompetto C. Abnormalities of sensorimotor integration in focal dystonia: a transcranial magnetic stimulation study. Brain $124(\mathrm{Pt}$ 3):537-545, 2001. 
94. Bara-Jimenez W, Shelton P, Hallett M. Spatial discrimination is abnormal in focal hand dystonia. Neurology 55:1869-1873, 2000.

95. Merzenich M, Wright B, Jenkins W, Xerri C, Byl N, Miller S, et al. Cortical plasticity underlying perceptual, motor, and cognitive skill development: implications for neurorehabilitation. Cold Spring Harb Symp Quant Biol 61:1-8, 1996.

96. Blake DT, Byl NN, Cheung S, Bedenbaugh P, Nagarajan S, Lamb $\mathrm{M}$, et al. Sensory representation abnormalities that parallel focal hand dystonia in a primate model. Somatosens Mot Res 19:347357, 2002.

97. Byl NN, Merzenich MM, Jenkins WM. A primate genesis model of focal dystonia and repetitive strain injury: I. Learning-induced dedifferentiation of the representation of the hand in the primary somatosensory cortex in adult monkeys. Neurology 47:508-520, 1996.

98. Byl NN. Focal hand dystonia may result from aberrant neuroplasticity. Adv Neurol 94:19-28, 2004.

99. Byl NN. What can we learn from animal models of focal hand dystonia? Rev Neurol (Paris) 159(10 Pt 1):857-873, 2003.

100. Byl NN, McKenzie A, Nagarajan SS. Differences in somatosensory hand organization in a healthy flutist and a flutist with focal hand dystonia: a case report. J Hand Ther 13:302-309, 2000.

101. Blake DT, Byl NN, Merzenich MM. Representation of the hand in the cerebral cortex. Behav Brain Res 135:179-184, 2002.

102. Sanger TD, Merzenich MM. Computational model of the role of sensory disorganization in focal task-specific dystonia. J Neurophysiol 84:2458-2464, 2000.

103. Merzenich MM, Jenkins WM. Reorganization of cortical representations of the hand following alterations of skin inputs induced by nerve injury, skin island transfers, and experience. $J$ Hand Ther 6:89-104, 1993.

104. Merzenich MM, Sameshima K. Cortical plasticity and memory. Curr Opin Neurobiol 3:187-196, 1993.

105. Donoghue JP. Plasticity of adult sensorimotor representations. Curr Opin Neurobiol 5:749-754, 1995.

106. Fox K, Glazewski S, Schulze S. Plasticity and stability of somatosensory maps in thalamus and cortex. Curr Opin Neurobiol 10:494-497, 2000.

107. Jones EG. Cortical and subcortical contributions to activity-dependent plasticity in primate somatosensory cortex. Annu Rev Neurosci 23:1-37, 2000.

108. Krupa DJ, Nicolelis MA. Network level properties of short-term plasticity in the somatosensory system. Prog Brain Res 128:161$172,2000$.

109. Kaas JH. The reorganization of somatosensory and motor cortex after peripheral nerve or spinal cord injury in primates. Prog Brain Res 128:173-179, 2000.

110. Chen R, Cohen LG, Hallett M. Nervous system reorganization following injury. Neuroscience 111:761-773, 2002.

111. Erzurumlu RS. Somatosensory cortical plasticity: recruiting silenced barrels by active whiskers. Exp Neurol 184:565-569, 2003.

112. Pantev C, Ross B, Fujioka T, Trainor LJ, Schulte M, Schulz M. Music and learning-induced cortical plasticity. Ann NY Acad Sci 999:438-450, 2003.

113. Wall JT, Xu J, Wang X. Human brain plasticity: an emerging view of the multiple substrates and mechanisms that cause cortical changes and related sensory dysfunctions after injuries of sensory inputs from the body. Brain Res Brain Res Rev 39:181215, 2002.

114. Wang X, Merzenich MM, Sameshima K, Jenkins WM. Remodelling of hand representation in adult cortex determined by timing of tactile stimulation. Nature 378:71-75, 1995.

115. Byl NN, Merzenich MM, Cheung S, Bedenbaugh P, Nagarajan SS, Jenkins WM. A primate model for studying focal dystonia and repetitive strain injury: effects on the primary somatosensory cortex. Phys Ther 77:269-284, 1997.

116. Topp KS, Byl NN. Movement dysfunction following repetitive hand opening and closing: anatomical analysis in owl monkeys. Mov Disord 14:295-306, 1999.

117. Rothwell JC, Huang YZ. Systems-level studies of movement disorders in dystonia and Parkinson's disease. Curr Opin Neurobiol 13:691-695, 2003.

118. Elston JS, Granje FC, Lees AJ. The relationship between eyewinking tics, frequent eye-blinking and blepharospasm. J Neurol Neurosurg Psychiatry 52:477-480, 1989.

119. Elston JS, Marsden CD, Grandas F, Quinn NP. The significance of ophthalmological symptoms in idiopathic blepharospasm. Eye 2(Pt 4):435-439, 1988.

120. Evinger C, Bao JB, Powers AS, Kassem IS, Schicatano EJ, Henriquez VM, et al. Dry eye, blinking, and blepharospasm. Mov Disord 17 [Suppl 2]:S75-S78, 2002.

121. Jankovic J, Orman J Blepharospasm: demographic and clinical survey of 250 patients. Ann Ophthalmol 16:371-376, 1984.

122. Langlois M, Richer F, Chouinard S. New perspectives on dystonia. Can J Neurol Sci 30 [Suppl 1]:S34-S44, 2003.

123. Schmidt KE, Linden DE, Goebel R, Zanella FE, Lanfermann H, Zubcov AA. Striatal activation during blepharospasm revealed by fMRI. Neurology 60:1738-1743, 2003.

124. Kerrison JB, Lancaster JL, Zamarripa FE, Richardson LA, Morrison JC, Holck DE, et al. Positron emission tomography scanning in essential blepharospasm. Am J Ophthalmol 136:846-852, 2003.

125. Hutchinson M, Nakamura T, Moeller JR, Antonini A, Belakhlef A, Dhawan V, et al. The metabolic topography of essential blepharospasm: a focal dystonia with general implications. Neurology 55:673-677, 2000.

126. Esmaeli-Gutstein B, Nahmias C, Thompson M, Kazdan M, Harvey J Positron emission tomography in patients with benign essential blepharospasm. Ophthal Plast Reconstr Surg 15:23-27, 1999.

127. Baker RS, Andersen AH, Morecraft RJ, Smith CD. A functional magnetic resonance imaging study in patients with benign essential blepharospasm. J Neuroophthalmol 23:11-15, 2003.

128. Peshori KR, Schicatano EJ, Gopalaswamy R, Sahay E, Evinger C. Aging of the trigeminal blink system. Exp Brain Res 136:351363, 2001.

129. Karson CN. Spontaneous eye-blink rates and dopaminergic systems. Brain 106(Pt 3):643-653, 1983.

130. Karson CN. Blinking. Bull Soc Belge Ophtalmol 237:443-457, 1989.

131. Zametkin AJ, Stevens JR, Pittman R. Ontogeny of spontaneous blinking and of habituation of the blink reflex. Ann Neurol 5:453457, 1979.

132. Bartko G, Herczeg I, Zador G. Blink rate response to haloperidol as possible predictor of therapeutic outcome. Biol Psychiatry 27:113-115, 1990.

133. Blin O, Masson G, Azulay JP, Fondarai J, Serratrice G. Apomorphine-induced blinking and yawning in healthy volunteers. $B r J$ Clin Pharmacol 30:769-773, 1990.

134. Taylor JR, Elsworth JD, Lawrence MS, Sladek JR Jr, Roth RH, Redmond DE Jr. Spontaneous blink rates correlate with dopamine levels in the caudate nucleus of MPTP-treated monkeys. Exp Neurol 158:214-220, 1999.

135. Elsworth JD, Lawrence MS, Roth RH, Taylor JR, Mailman RB, Nichols DE, et al. D1 and D2 dopamine receptors independently regulate spontaneous blink rate in the vervet monkey. J Pharmacol Exp Ther 259:595-600, 1991.

136. Napolitano A, Bonuccelli U, Rossi B. Different effects of levodopa and apomorphine on blink reflex recovery cycle in essential blepharospasm. Eur Neurol 38:119-122, 1997.

137. Evinger C, Basso MA, Manning KA, Sibony PA, Pellegrini JJ, Horn AK. A role for the basal ganglia in nicotinic modulation of the blink reflex. Exp Brain Res 92:507-515, 1993.

138. Baker RS, Radmanesh SM, Abell KM. The effect of apomorphine on blink kinematics in subhuman primates with and without facial nerve palsy. Invest Ophthalmol Vis Sci 43:2933-2938, 2002.

139. Kimura J Disorder of interneurons in Parkinsonism. The orbicularis oculi reflex to paired stimuli. Brain 96:87-96, 1973.

140. Basso MA, Strecker RE, Evinger C. Midbrain 6-hydroxydopamine lesions modulate blink reflex excitability. Exp Brain Res 94:88-96, 1993.

141. Schicatano EJ, Peshori KR, Gopalaswamy R, Sahay E, Evinger 
C. Reflex excitability regulates prepulse inhibition. J Neurosci 20:4240-4247, 2000.

142. Goto S, Kihara K, Hamasaki T, Nishikawa S, Hirata Y, Ushio Y. Apraxia of lid opening is alleviated by pallidal stimulation in a patient with Parkinson's disease. Eur J Neurol 7:337-340, 2000.

143. Esteban A, Gimenez-Roldan S. Involuntary closure of eyelids in parkinsonism. Electrophysiological evidence for prolonged inhibition of the levator palpebrae muscles. J Neurol Sci 85:333-345, 1988.

144. Ferguson IT, Lenman JA, Johnston BB. Habituation of the orbicularis oculi reflex in dementia and dyskinetic states. J Neurol Neurosurg Psychiatry 41:824-828, 1978.

145. Rey RD, Garretto NS, Bueri JA, Simonetti DD, Sanz OP, Sica RE. The effect of levodopa on the habituation of the acousticpalpebral reflex in Parkinson's disease. Electromyogr Clin Neurophysiol 36:357-360, 1996.

146. Sunohara N, Tomi H, Satoyoshi E, Tachibana S. Glabella tap sign. Is it due to a lack of R2-habituation? J Neurol Sci 70:257267, 1985.

147. Valls-Sole J, Valldeoriola F, Tolosa E, Marti MJ. Distinctive abnormalities of facial reflexes in patients with progressive supranuclear palsy. Brain 120(Pt 10):1877-1883, 1997.

148. Vidailhet M, Rothwell JC, Thompson PD, Lees AJ, Marsden CD. The auditory startle response in the Steele-Richardson-Olszewski syndrome and Parkinson's disease. Brain 115(Pt 4):1181-1192, 1992.

149. Larumbe R, Vaamonde J, Artieda J, Zubieta JL, Obeso JA. Reflex blepharospasm associated with bilateral basal ganglia lesion. Mov Disord 8:198-200, 1993.

150. Obeso JA, Artieda J, Marsden CD. Stretch reflex blepharospasm. Neurology 35:1378-1380, 1985.

151. Fisher CM. Reflex blepharospasm. Neurology 13:77-78, 1963.

152. Burkard WP, Bonetti EP, Da Prada M, Martin JR, Polc P, Schaffner R, et al. Pharmacological profile of moclobemide, a short-acting and reversible inhibitor of monoamine oxidase type A. J Pharmacol Exp Ther 248:391-399, 1989.

153. Mostofsky DI, Yehuda S, Rabinovitz S, Carasso R. The control of blepharospasm by essential fatty acids. Neuropsychobiology 41 : 154-157, 2000.

154. Basso MA, Powers AS, Evinger C. An explanation for reflex blink hyperexcitability in Parkinson's disease. I. Superior colliculus. J Neurosci 16:7308-7317, 1996.

155. Basso MA, Evinger C. An explanation for reflex blink hyperexcitability in Parkinson's disease. II. Nucleus raphe magnus. J Neurosci 16:7318-7330, 1996.

156. Wichmann T, DeLong MR. Pathophysiology of Parkinson's disease: the MPTP primate model of the human disorder. Ann NY Acad Sci 991:199-213, 2003.

157. Misbahuddin A, Placzek MR, Warner TT. Focal dystonia is associated with a polymorphism of the dopamine D5 receptor gene. Adv Neurol 94:143-146, 2004.

158. Misbahuddin A, Placzek MR, Chaudhuri KR, Wood NW, Bhatia KP, Warner TT. A polymorphism in the dopamine receptor DRD5 is associated with blepharospasm. Neurology 58:124-126, 2002.

159. Schicatano EJ, Basso MA, Evinger C. Animal model explains the origins of the cranial dystonia benign essential blepharospasm. J Neurophysiol 77:2842-2846, 1997.

160. Molloy FM, Carr TD, Zeuner KE, Dambrosia JM, Hallett M. Abnormalities of spatial discrimination in focal and generalized dystonia. Brain 126(Pt 10):2175-2182, 2003.

161. Mao JB, Evinger C. Long-term potentiation of the human blink reflex. J Neurosci 21:RC151, 2001.

162. Pellegrini JJ, Evinger C. Role of cerebellum in adaptive modification of reflex blinks. Learn Mem 4:77-87, 1997.

163. Morcuende S, Delgado-Garcia JM, Ugolini G. Neuronal premotor networks involved in eyelid responses: retrograde transneuronal tracing with rabies virus from the orbicularis oculi muscle in the rat. J Neurosci 22:8808-8818, 2002.

164. Delgado-Garcia JM, Gruart A. The role of interpositus nucleus in eyelid conditioned responses. Cerebellum 1:289-308, 2002.
165. Chen F-P EC. Two functions of blink-related interpositus neurons. Soc Neurosci Abstr 29:391.398, 2003.

166. Davis KD, Dostrovsky JO. Modulatory influences of red nucleus stimulation on the somatosensory responses of cat trigeminal subnucleus oralis neurons. Exp Neurol 91:80-101, 1986.

167. LeDoux MS, Hurst DC, Lorden JF. Single-unit activity of cerebellar nuclear cells in the awake genetically dystonic rat. Neuroscience 86:533-545, 1998

168. Campbell DB, Hess EJ. Cerebellar circuitry is activated during convulsive episodes in the tottering ( $\mathrm{tg} / \mathrm{tg})$ mutant mouse. $\mathrm{Neu}$ roscience 85:773-783, 1998.

169. Pizoli CE, Jinnah HA, Billingsley ML, Hess EJ. Abnormal cerebellar signaling induces dystonia in mice. $J$ Neurosci 22:78257833, 2002.

170. Raike RS, Jinnah HA, Hess EJ. Animal models of generalized dystonia. NeuroRx 2:504-512

171. LeDoux MS, Lorden JF. Abnormal cerebellar output in the genetically dystonic rat. Adv Neurol 78:63-78, 1998.

172. LeDoux MS, Lorden JF, Ervin JM. Cerebellectomy eliminates the motor syndrome of the genetically dystonic rat. Exp Neurol 120: 302-310, 1993.

173. Federico F, Simone IL, Lucivero V, Defazio G, De Salvia R, Mezzapesa DM, et al. Proton magnetic resonance spectroscopy in primary blepharospasm. Neurology 51:892-895, 1998.

174. Carbon M, Su S, Dhawan V, Raymond D, Bressman S, Eidelberg D. Regional metabolism in primary torsion dystonia: effects of penetrance and genotype. Neurology 62:1384-1390, 2004.

175. Ledoux MS, Lorden JF, Ervin JM. Inferior olive serotonin and norepinephrine levels during development in the genetically dystonic rat. Brain Res Bull 33:299-305, 1994.

176. Richter A, Loscher W. Animal models of paroxysmal dystonia. Adv Neurol 89:443-451, 2002.

177. Siep E, Richter A, Loscher W, Speckmann EJ, Kohling R. Sodium currents in striatal neurons from dystonic $\mathrm{dt}(\mathrm{sz})$ hamsters: altered response to lamotrigine. Neurobiol Dis 9:258-268, 2002.

178. Richter A, Loscher W. Animal models of dystonia. Funct Neurol 15:259-267, 2000.

179. Gernert M, Hamann M, Bennay M, Loscher W, Richter A. Deficit of striatal parvalbumin-reactive GABAergic interneurons and decreased basal ganglia output in a genetic rodent model of idiopathic paroxysmal dystonia. J Neurosci 20:7052$7058,2000$.

180. Rehders JH, Loscher W, Richter A. Evidence for striatal dopaminergic overactivity in paroxysmal dystonia indicated by microinjections in a genetic rodent model. Neuroscience 97:267-277, 2000.

181. Nobrega JN, Parkes JH, Wong P, Raymond R, Richter A. Altered expression of preproenkephalin and prodynorphin mRNA in a genetic model of paroxysmal dystonia. Brain Res 1015:87-95, 2004

182. Kohling R, Koch UR, Hamann M, Richter A. Increased excitability in cortico-striatal synaptic pathway in a model of paroxysmal dystonia. Neurobiol Dis 16:236-245, 2004.

183. Gernert M, Richter A, Loscher W. Alterations in spontaneous single unit activity of striatal subdivisions during ontogenesis in mutant dystonic hamsters. Brain Res 821:277-285, 1999.

184. Richter A, Loscher W. Pathology of idiopathic dystonia: findings from genetic animal models. Prog Neurobiol 54:633-677, 1998.

185. Nobrega JN, Richter A, Jiwa D, Raymond R, Loscher W. Regional alterations in neuronal activity in dystonic hamster brain determined by quantitative cytochrome oxidase histochemistry. Neuroscience 83:1215-1223, 1998.

186. Gernert M, Richter A, Loscher W. The electrical activity is impaired in the red nucleus of $\mathrm{dt}(\mathrm{sz})$ mutant hamsters with paroxysmal dystonia: an EEG power spectrum analysis of depth electrode recordings. Brain Res 760:102-108, 1997.

187. Dean P, Porrill J, Stone JV. Visual awareness and the cerebellum: possible role of decorrelation control. Prog Brain Res 144:61-75, 2004.

188. Dean P, Porrill J, Stone JV. Decorrelation control by the cerebellum achieves oculomotor plant compensation in simulated 
vestibulo-ocular reflex. Proc R Soc Lond B Biol Sci 269:18951904, 2002.

189. Porrill J, Dean P, Stone JV. Recurrent cerebellar architecture solves the motor-error problem. Proc R Soc Lond B Biol Sci 271:789-796, 2004.

190. Ebadzadeh M, Darlot C. Cerebellar learning of bio-mechanical functions of extra-ocular muscles: modeling by artificial neural networks. Neuroscience 122:941-966, 2003.
191. Blazquez PM, Hirata Y, Highstein SM. The vestibulo-ocular reflex as a model system for motor learning: what is the role of the cerebellum? Cerebellum 3:188-192, 2004.

192. Mink JW. The basal ganglia and involuntary movements: impaired inhibition of competing motor patterns. Arch Neurol 60: 1365-1368, 2003.

193. Perlmutter JS, Mink JW. Dysfunction of dopaminergic pathways in dystonia. Adv Neurol 94:163-170, 2004. 